\title{
Hormonal therapy followed by chemotherapy or the reverse sequence as first-line treatment of hormone-responsive, human epidermal growth factor receptor-2 negative metastatic breast cancer patients: results of an observational study
}

\author{
Claudia Bighin ${ }^{1}$, Beatrice Dozin², Francesca Poggio', Marcello Ceppi ${ }^{2}$, Paolo \\ Bruzzi $^{2}$, Alessia D'Alonzo ${ }^{1}$, Alessia Levaggi ${ }^{1}$, Sara Giraudi ${ }^{1}$, Matteo Lambertini ${ }^{1}$, \\ Loredana Miglietta ${ }^{1}$, Marina Vaglica ${ }^{1}$, Vincenzo Fontana ${ }^{2}$, Giuseppina Iacono ${ }^{1}$, \\ Paolo Pronzato ${ }^{1}$ and Lucia Del Mastro ${ }^{1}$ \\ ${ }^{1}$ Department of Medical Oncology, IRCCS Azienda Ospedaliera Universitaria San Martino - Istituto Nazionale per la Ricerca \\ sul Cancro, Genoa, Italy \\ 2 Department of Clinical Epidemiology, IRCCS Azienda Ospedaliera Universitaria San Martino - Istituto Nazionale per la \\ Ricerca sul Cancro, Genoa, Italy \\ Correspondence to: Claudia Bighin, email: claudia.bighin@hsanmartino.it \\ Keywords: advanced breast cancer, hormone-responsive breast cancer, first-line treatment, hormonal therapy, chemotherapy \\ Received: November 30, $2016 \quad$ Accepted: January 10,2017 Published: January 18, 2017
}

Copyright: Bighin et al. This is an open-access article distributed under the terms of the Creative Commons Attribution License 3.0 (CC BY 3.0), which permits unrestricted use, distribution, and reproduction in any medium, provided the original author and source are credited.

\section{ABSTRACT}

Introduction Although hormonal-therapy is the preferred first-line treatment for hormone-responsive, HER2 negative metastatic breast cancer, no data from clinical trials support the choice between hormonal-therapy and chemotherapy.

Methods Patients were divided into two groups according to the treatment: chemotherapy or hormonal-therapy. Outcomes in terms of clinical benefit and median overall survival (OS) were retrospectively evaluated in the two groups. To calculate the time spent in chemotherapy with respect to OS in the two groups, the proportion of patients in chemotherapy relative to those present in either group was computed at every day from the start of therapy.

Results From 1999 to 2013, 119 patients received first-line hormonal-therapy (HT-first group) and 100 first-line chemotherapy (CT-first group). Patients in the CTfirst group were younger and with poorer prognostic factors as compared to those in HT-first group. Clinical benefit (77 vs $81 \%$ ) and median OS (50.7 vs 51.1 months) were similar in the two groups. Time spent in chemotherapy was significantly longer during the first 3 years in CT-first group (54-34\%) as compared to the HT-first group $(11-18 \%)$. This difference decreased after the third year and overall was $28 \%$ in the CT-first group and $18 \%$ in the HT-first group.

Conclusions The sequence first-line chemotherapy followed by hormonal-therapy, as compared with the opposite sequence, is associated with a longer time of OS spent in chemotherapy. However, despite the poorer prognostic factors, patients in the CTfirst group had a superimposable OS than those in the HT-first group.

\section{INTRODUCTION}

Breast cancer is not a single disease and it is now accepted that there are at least four different biological subtypes which comprise endocrine responsive disease divided in Luminal A (estrogen receptor [ER] and/or progesterone receptor $[\mathrm{PgR}]$ positive $(+)$, HER2 negative
(-), low proliferating activity) and Luminal B (ER and/or PgR+, HER2-, high proliferating activity), HER2+ disease (HER2+ regardless of hormone receptor status) and triplenegative disease (ER, PgR and HER2 negative [1-3].

The absolute majority of all newly diagnosed breast cancer patients (about 60-65\%) [4] has hormone receptor positive $(\mathrm{HR}+)$ tumors; despite the best prognosis, still 
many patients relapse after treatment, forming the most common subtype of metastatic breast cancer (MBC) patients [5].

With current treatments, the median overall survival of $\mathrm{HR}+\mathrm{MBC}$ patients is estimated to be greater than 50 months [6] and it is crucial to plan the best sequence of treatments as it is expected that these patients receive multiple lines of therapy.

Most of $\mathrm{HR}+\mathrm{MBC}$ patients are treated with both hormonal therapy (HT) and chemotherapy (CT) during the course of their disease.

International guidelines indicate that HT is the preferred first-line treatment option for these patients [7-10] restricting the use of CT only to patients not responsive to HT or at risk of visceral crisis. However, this indication derives mostly from expert opinions and from very few randomized controlled trials.

A systematic review of trials comparing HT with $\mathrm{CT}$ as first-line treatment of MBC showed no significant difference in overall survival (OS) between the two types of treatment and an increased toxicity associated with CT [11]. However, no modern drugs, such as aromatase inhibitors or taxanes, were used in these trials and patients included in the CT arms did not receive maintenance HT after CT, which is now currently administered, although without a strong level of evidence [12].

Therefore, there are no strong data supporting that delivering first HT and CT thereafter provides a better outcome in terms of OS as compared to the reverse sequence.

The aim of the present study is to retrospectively compare the two treatment sequences in terms of objective response rate (ORR), clinical benefit rate (CBR), progression-free survival (PFS), OS, CT duration and time spent in CT (related to OS) in HR+/HER2- MBC patients.

\section{MATERIALS AND METHODS}

All consecutive $\mathrm{MBC}$ patients treated with a first-line therapy (CT or HT with or without biological therapy) from 1999 to 2013 were included in this monocentric retrospective observational study. Patients were classified in four subgroups according to the biological characteristics of their primary tumor: Luminal A (ER and/or PgR+, HER2- and Ki67 < 20\%), Luminal B (ER and/or PgR+, HER2- and Ki67 $\geq 20 \%$ ), HER+ (immunohistochemistry score of $3+$ or fluorescence in situ hybridization amplified regardless of hormonal status), and Triple-Negative (ER and PgR and HER2 negative) [13].

For the present study, we selected only Luminal A and $\mathrm{B}$ patients treated with at least one line of HT or one line of CT. Eligible patients were divided into two groups: the HT-first group including patients receiving HT as firstline treatment and the CT-first group including patients receiving $\mathrm{CT}$ as first-line treatment.
The choice between first-line HT or CT was performed by the treating physician on the basis of patients' and disease characteristics.

Patients' characteristics, histological and biological data from primary tumor, treatment history with clinical response at each line of treatment, PFS and survival data were collected.

\section{Statistical analysis}

Patient and disease characteristics were analyzed using descriptive statistics. For each prognostic factor, heterogeneity between the two study groups was estimated by the Pearson Chi-square test or the Mann-Withney test.

Clinical response to therapy was assessed at the end of the first-line of treatment by clinical examination and imaging procedures, and classified according to RECIST guidance [14] . Objective response was defined as complete response (CR) if there was no evidence of residual tumor at the metastasis (MTS) site(s), partial response (PR) if the MTS mass was reduced by at least $50 \%$. An increase in MTS size by $25 \%$ (as compared to baseline measurement) or new MTS appearance was considered as disease progression (PD). If the criteria for objective response or progression were not met, the disease was considered as stable (SD). Patients who experienced $\mathrm{CR}, \mathrm{PR}$ or $\mathrm{SD}$ were considered as having obtained a CB from the therapy.

OS was estimated from the date of MTS diagnosis to the date of last contact or death from any cause.

Distant disease-free survival (DDFS) was estimated from the date of diagnosis of the primary tumor and the date of MTS diagnosis.

PFS was estimated from the date of first-line MBC therapy to the date of first subsequent PD.

Survival curves were obtained using the KaplanMeier method and differences between treatment sequences were assessed by the log-rank test [15].

Cox regression models were used for multivariate analysis to assess the independent role of each prognostic factor with respect to OS, while adjusting for the effects of the other factors. The variables included in the model as covariates were patient age at the time of relapse, menopausal status, tumor stage at diagnosis, sequence of systemic treatment (HT-first vs CT-first), median DDFS, presence of de novo metastatic disease, number of MTS sites, presence of visceral MTS (liver, lung and/or brain), presence of non-visceral MTS (bone, lymph node, skin and/or others). The multivariate analyses started from the full model, with all covariates included. Factors not significantly associated with survival were removed from the model by means of a step-down procedure based on the likelihood ratio test.

In subgroup analyses, effects of the CT-first sequence as compared to the HT-first sequence across the strata of each covariate were assessed by introducing the 
Table 1: Patient and disease characteristics by treatment group

\begin{tabular}{|c|c|c|c|}
\hline & HT-first group (\%) & CT-first group (\%) & $p^{\pi}$ \\
\hline Total number of patients & $119(54)$ & $100(46)$ & \\
\hline $\begin{array}{l}\text { Median age - year (range) } \\
\text { At primary tumor diagnosis } \\
\text { At metastasis diagnosis }\end{array}$ & $\begin{array}{l}61(33-93) \\
67(37-93)\end{array}$ & $\begin{array}{l}54(32-82) \\
57(32-85)\end{array}$ & $\begin{array}{l}0.049 \\
<0.001\end{array}$ \\
\hline $\begin{array}{l}\text { Menopausal status } \\
\text { Premenopausal } \\
\text { Postmenopausal }\end{array}$ & $\begin{array}{l}31(26) \\
88(74)\end{array}$ & $\begin{array}{l}45(45) \\
55(55)\end{array}$ & 0.003 \\
\hline $\begin{array}{l}\text { Stage at diagnosis } \\
\text { I } \\
\text { II } \\
\text { III } \\
\text { missing }\end{array}$ & $\begin{array}{l}19(19) \\
35(35) \\
44(44) \\
2(2) \\
\end{array}$ & $\begin{array}{l}14(22) \\
17(27) \\
32(51) \\
- \\
\end{array}$ & 0.454 \\
\hline $\begin{array}{l}\text { De novo metastatic disease (stage IV) } \\
\text { Yes } \\
\text { No } \\
\end{array}$ & $\begin{array}{l}19(16) \\
100(84) \\
\end{array}$ & $\begin{array}{l}37(37) \\
63(63) \\
\end{array}$ & 0.001 \\
\hline $\begin{array}{l}\text { Adjuvant/Neoadjuvant } \text { CT }^{\#} \\
\text { Anthracycline alone / or + other } \\
\text { Taxane alone / or + other } \\
\text { Anthracycline and taxane alone / or+ other } \\
\text { Other } \\
\text { None }\end{array}$ & $\begin{array}{l}4(4) \\
19(19) \\
21(21) \\
25(25) \\
31(31)\end{array}$ & $\begin{array}{l}- \\
31(49) \\
14(22) \\
18(29) \\
-\end{array}$ & $<0.001$ \\
\hline $\begin{array}{l}\text { Adjuvant/Neoadjuvant } \boldsymbol{H T}^{\sharp} \\
\text { Only Tamoxifen } \\
\text { Aromatase Inhibitors } \\
\text { Tamoxifen } \rightarrow \text { Aromatase Inhibitors } \\
\text { None } \\
\text { Missing }\end{array}$ & $\begin{array}{l}49(49) \\
26(26) \\
12(12) \\
12(12) \\
-\end{array}$ & $\begin{array}{l}28(45) \\
14(23) \\
10(15) \\
10(15) \\
1(2)\end{array}$ & 0.570 \\
\hline $\begin{array}{c}\text { Disease-free survival }^{\#}, \text { months } \\
\quad \leq 12 \\
>12-36 \\
>36 \\
\end{array}$ & $\begin{array}{ll}6 & (6) \\
28 & (29) \\
64 & (65) \\
\end{array}$ & $\begin{array}{l}16(25) \\
45(72) \\
5\end{array}$ & 0.599 \\
\hline $\begin{array}{l}\text { Number of metastatic sites } \\
1 \\
2 \\
\geq 3\end{array}$ & $\begin{array}{l}76(64) \\
24(20) \\
19(16)\end{array}$ & \begin{tabular}{|l|}
$45(45)$ \\
$23(23)$ \\
$32(32)$
\end{tabular} & 0.008 \\
\hline $\begin{array}{l}\text { Sites of metastasis } \\
\text { Liver - yes } \\
\text { no }\end{array}$ & $\begin{array}{l}14(12) \\
105(88)\end{array}$ & $\begin{array}{l}35(35) \\
65(65)\end{array}$ & $<0.001$ \\
\hline $\begin{array}{r}\text { Lung }- \text { yes } \\
\text { No }\end{array}$ & $\begin{array}{l}15(13) \\
104(87)\end{array}$ & $\begin{array}{l}25(25) \\
75(75)\end{array}$ & $<0.001$ \\
\hline $\begin{array}{r}\text { Liver and Lung }- \text { yes } \\
\text { No }\end{array}$ & $\begin{array}{l}3(2) \\
116(98)\end{array}$ & $\begin{array}{l}7(7) \\
93(93)\end{array}$ & 0.114 \\
\hline $\begin{array}{c}\text { Brain - yes } \\
\text { no }\end{array}$ & $\begin{array}{l}1(1) \\
118(99)\end{array}$ & $\begin{array}{l}3(3) \\
97(97)\end{array}$ & 0.234 \\
\hline $\begin{array}{r}\text { Bone - yes } \\
\text { no }\end{array}$ & $\begin{array}{l}79(67) \\
40(33)\end{array}$ & $\begin{array}{l}60(60) \\
40(40)\end{array}$ & 0.328 \\
\hline $\begin{array}{r}\text { Lymph node }- \text { yes } \\
\text { no }\end{array}$ & $\begin{array}{l}46(39) \\
73(61)\end{array}$ & \begin{tabular}{|l}
$41(41)$ \\
$59(59)$ \\
\end{tabular} & 0.724 \\
\hline
\end{tabular}

TP values: from Pearson Chi-square test for categorical variables; from Mann-Withney test for continuous variable (age); \#Metastatic ab initio excluded; Abbreviations: HT: hormonal-therapy; CT: chemotherapy

appropriate interaction terms in the Cox model. These covariates by treatment interaction terms were introduced in the model one at a time. The likelihood ratio test was used to evaluate the statistical significance of each interaction term.
Logistic regressions were used to predict a relationship between the use of $\mathrm{CT}$ as first-line treatment and the following factors: patient age at the time of MTS diagnosis, menopausal status, presence of de novo metastatic disease, number of MTS sites and type of MTS 
(visceral versus non-visceral). All statistical analyses were two-sided and were carried out using the SPSS package (version 18.0 for Windows). Significance was accepted for $P$ values $<0.05$.

With the aim of calculating the time spent in CT with respect to OS in the two patients groups, the proportion of patients in CT relative to those present in either group was computed at every day from the start of therapy. To adjust for OS, the proportions of patients in CT were weighted using as weights the survival function of the two groups. The weighted proportions were summed along time to estimate the cumulative average proportion of time patients spent in CT until then. For each proportion the $95 \%$ confidence intervals, based on the binomial distribution, were computed. LOWESS smoothing method has been applied to highlight the trend of proportions [16].

\section{RESULTS}

Three hundred twenty-nine patients with MBC were identified and 219 were included for this analysis

(Figure 1). Of the 110 patients who were excluded 60 were HER2+, 37 were triple-negative, 4 patients received $\mathrm{CT}$ concomitantly with $\mathrm{HT}$ as first-line treatment, 4 patients had a second non-breast tumor before the diagnosis of MTS and 2 patients did not receive any systemic therapy for their disease.

One hundred nineteen patients (54\%) with hormoneresponsive HER2- MBC received HT as first-line treatment with or without following CT (HT-first group) while $100(46 \%)$ patients were treated with a first-line CT with or without following HT (CT-first group).

Table 1 summarizes patients and disease characteristics.

Median age at MTS diagnosis was 64 years (range 32-93); patients in the CT-first group were younger (median age 57 versus 67 years, $p<0.001$ ) and more frequently in pre-menopausal status ( $45 \%$ versus $26 \%, p$ $=0.003$ ) as compared to patients in the HT-first group.

Patients in the CT-first group were initially diagnosed at a more advanced stage as compared to patients in the HT-first group (37\% versus $16 \%$ in stage IV, $p=0.0014$ ) but DDFS between the primary tumor and the appearance of MTS was similar in the two treatment groups $(p=0.599)$. As expected, patients in the CT-first group had more metastatic sites ( $\geq 3$ in $32 \%$ versus $16 \%$, $p=0.008$ ) and a greater liver or lung involvement than patients in the HT-first group (35\% and $25 \%$ versus $12 \%$ and $13 \%$, respectively, $p<0.001)$. Nevertheless, the occurrence of concomitant liver and lung metastases was

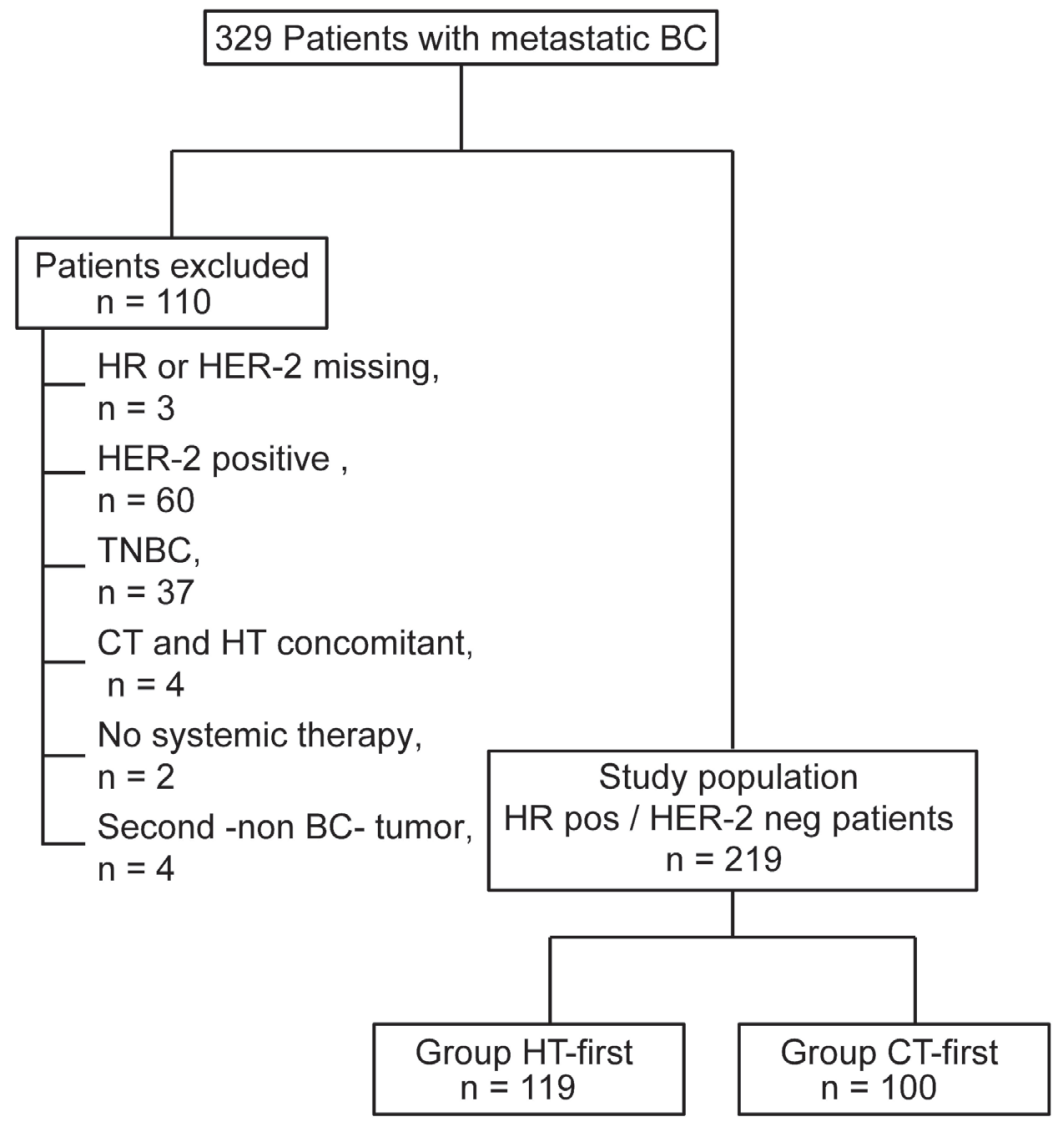

Figure 1: Flow-chart for the selection of the patient population to be included in the study. 
Table 2: MBC therapy characteristics by treatment group

\begin{tabular}{|c|c|c|c|}
\hline & HT-first group (\%) & CT-first group (\%) & $p^{\mathbb{\top}}$ \\
\hline Median number of HT lines (range) & $2(1-5)$ & $1(0-5)$ & $<0.001$ \\
\hline $\begin{array}{l}\text { Total number of HT lines } \\
0 \\
1 \\
2 \\
3 \\
>3\end{array}$ & $\begin{array}{l}0(0) \\
119(100) \\
80(67) \\
48(40) \\
33(28)\end{array}$ & $\begin{array}{ll}23 & (23) \\
77 & (77) \\
45 & (45) \\
24 & (24) \\
11 & (11)\end{array}$ & \\
\hline Median total HT duration, months (range) & $20.7(1.8-200.7)$ & $19.3(0.5-116.8)$ & 0.692 \\
\hline Median number of CT lines (range) & $1(0-6)$ & $2(1-7)$ & $<0.001$ \\
\hline $\begin{array}{l}\text { Total number of CT lines } \\
0 \\
1 \\
2 \\
3 \\
4 \\
>4\end{array}$ & \begin{tabular}{|ll}
42 & $(35)$ \\
77 & $(68)$ \\
56 & $(47)$ \\
35 & $(29)$ \\
13 & $(11)$ \\
18 & $(15)$ \\
\end{tabular} & \begin{tabular}{|l}
$0(0)$ \\
$100(100)$ \\
$56(56)$ \\
$36(36)$ \\
$24(24)$ \\
$17(17)$ \\
\end{tabular} & \\
\hline Median total CT duration, months (range) & $11.3(0.2-38.2)$ & $8.3(0.03-53.2)$ & 0.318 \\
\hline $\begin{array}{l}\text { First line chemotherapy } \\
\text { Polychemotherapy } \\
\text { Monochemotherapy } \\
\text { None } \\
\text { Missing }\end{array}$ & $\begin{array}{l}26(22) \\
51(43) \\
42(35) \\
0(0)\end{array}$ & $\begin{array}{l}56(56) \\
43(43) \\
0(0) \\
1(1)\end{array}$ & 0.004 \\
\hline $\begin{array}{l}\text { Type of CT at first line } \\
\text { Anthracycline alone } \\
\text { Taxane alone } \\
\text { Anthracycline and taxane } \\
\text { Taxane and other } \\
\text { Other } \\
\text { No CT }\end{array}$ & $\begin{array}{l}2(2) \\
12(10) \\
9(8) \\
12(10) \\
42(35) \\
42(35)\end{array}$ & $\begin{array}{l}9(9) \\
16(16) \\
27(27) \\
19(19) \\
29(29) \\
0(0)\end{array}$ & 0.004 \\
\hline $\begin{array}{l}\text { Type of HT at first line } \\
\text { Tamoxifen } \\
\text { Non-steroidal aromatase inhibitor } \\
\text { Steroidal aromatase inhibitor } \\
\text { Fulvestrant } \\
\text { Everolimus } \\
\text { Other } \\
\text { No HT }\end{array}$ & $\begin{array}{ll}11 & (9) \\
57 & (48) \\
19 & (16) \\
27 & (23) \\
1 & (1) \\
4 & (3) \\
0 & (0)\end{array}$ & $\begin{array}{l}13(13) \\
43(43) \\
9(9) \\
11(11) \\
1(1) \\
0(0) \\
23(23)\end{array}$ & $<0.001$ \\
\hline
\end{tabular}

$\Phi P$ values: from Pearson Chi-square test for categorical variables; from Mann-Withney test for continuous variable; Abbreviations: HT: hormonal-therapy; CT: chemotherapy

similarly low in the two treatment groups $(2 \%$ and $7 \%, p$ $=0.114)$.

Considering only patients with stage I to III primary tumors, delivery of neo/adjuvant chemotherapy regimen differed between the two groups $(p<0.001)$ : in particular, taxane alone or in combination with other drugs were delivered more often in the CT-first group than in the HTfirst group (49\% versus 19\%). All patients in the CT-first group underwent at least one type of $\mathrm{CT}$ regimen while about one third (31\%) of patients in the HT-first group did not receive any.

Neo/adjuvant hormonal therapy was given to a similar proportion of patients in the two treatment groups.

At the time of this analysis, in the HT-first group 42 patients $(35 \%)$ did not have yet received any CT and, conversely, in the CT-first group 23 patients (23\%) did not have yet receive any HT (Table 2).
The median numbers of lines of treatments (HT plus CT) was similar in the two groups: 4 (range 1-10) in HT-first group and 3 (range 1-11) in CT-first group. No significant difference in the total duration of HT was observed between the two groups (median duration: 20.7 and 19.3 months in the HT-first and CT-first groups, respectively, $p=0.692$ ). The total $\mathrm{CT}$ duration was similar in the two treatment groups (11.3 and 8.3 months in the HT-first and CT-first groups, respectively, $p=0.318$ ).

A maintenance HT after first-line CT was administered in 63 patients $(63 \%)$ in the CT-first group and letrozole was the most widely used drug (about 52\% of patients).

Patients in the CT-first group received more frequently a poly-CT as first-line CT than patients in HTfirst group (56\% versus $22 \%$ ). Among those patients in the CT-first group who received poly-CT, about one third 
Table 3: Prognostic factors associated with a preferential use of CT as first-line treatment of MBC

\begin{tabular}{|c|c|c|c|c|c|c|}
\hline \multirow[t]{2}{*}{ Prognostic factor } & \multicolumn{3}{|c|}{ Univariate } & \multicolumn{3}{|c|}{ Multivariate } \\
\hline & OR & $95 \% \mathrm{CI}$ & $p$ & OR & $95 \% \mathrm{CI}$ & $p$ \\
\hline $\begin{array}{l}\text { Age } \\
\leq 65 \text { years } \\
>65 \text { years }\end{array}$ & $\begin{array}{c}1 \text { (ref) } \\
0.33\end{array}$ & $0.21-0.53$ & $<0.001$ & $\begin{array}{c}1 \text { (ref) } \\
0.29\end{array}$ & $0.17-0.49$ & $<0.001$ \\
\hline $\begin{array}{l}\text { Menopausal status } \\
\text { premenopause } \\
\text { postmenopause }\end{array}$ & $\begin{array}{c}1 \text { (ref) } \\
0.40 \\
\end{array}$ & $0.24-0.66$ & 0.004 & $\begin{array}{c}\mathrm{rfm} \\
- \\
\end{array}$ & $\begin{array}{l}- \\
-\end{array}$ & 0.102 \\
\hline $\begin{array}{l}\text { De novo metastatic disease } \\
\text { no } \\
\text { yes }\end{array}$ & $\begin{array}{c}1 \text { (ref) } \\
2.92\end{array}$ & $\begin{array}{c}- \\
1.64-5.17\end{array}$ & $<0.001$ & $\begin{array}{c}1 \text { (ref) } \\
2.89\end{array}$ & $\stackrel{-}{-}$ & 0.001 \\
\hline $\begin{array}{l}\text { Number of metastatic sites } \\
1 \\
2 \\
\geq 3\end{array}$ & $\begin{array}{l}1(\mathrm{ref}) \\
2.05 \\
2.91 \\
\end{array}$ & $\begin{array}{c}- \\
1.17-3.57 \\
1.59-5.34 \\
\end{array}$ & 0.001 & $\begin{array}{c}\mathrm{rfm} \\
- \\
- \\
\end{array}$ & $\begin{array}{l}- \\
- \\
-\end{array}$ & 0.400 \\
\hline $\begin{array}{l}\text { Metastasis type } \\
\text { non-visceral } \\
\text { visceral }\end{array}$ & $\begin{array}{c}1 \text { (ref) } \\
5.15 \\
\end{array}$ & 3.09-8.57 & $<0.001$ & $\begin{array}{c}1 \text { (ref) } \\
5.80\end{array}$ & 3.34- -10.06 & $<0.001$ \\
\hline $\begin{array}{l}\text { DDFS } \\
\leq \text { median of } 36.3 \text { months } \\
>\text { median of } 36.3 \text { months }\end{array}$ & $\begin{array}{c}1 \text { (ref) } \\
0.48\end{array}$ & $0.30-0.76$ & 0.002 & $\mathrm{rfm}$ & - & 0.412 \\
\hline
\end{tabular}

Abbreviations: *rfm, removed from the final model

(18 out of 56) had de novo metastatic disease. Poly-CT consisted of the combination of an anthracycline and a taxane more often in the CT-first group than in the HTfirst group (27\% versus $8 \%)$.

The most commonly drug used as first-line HT was a non-steroidal aromatase inhibitor (letrozole or anastrozole) in both groups (48\% versus $43 \%$ ) while fulvestrant was more frequently used as first-line HT in the HT-first group as compared to the CT-first group (23\% versus $11 \%$ ).

Only 2 patients ( 1 in HT-first group and 1 in CTfirst group) received everolimus in association with exemestane.

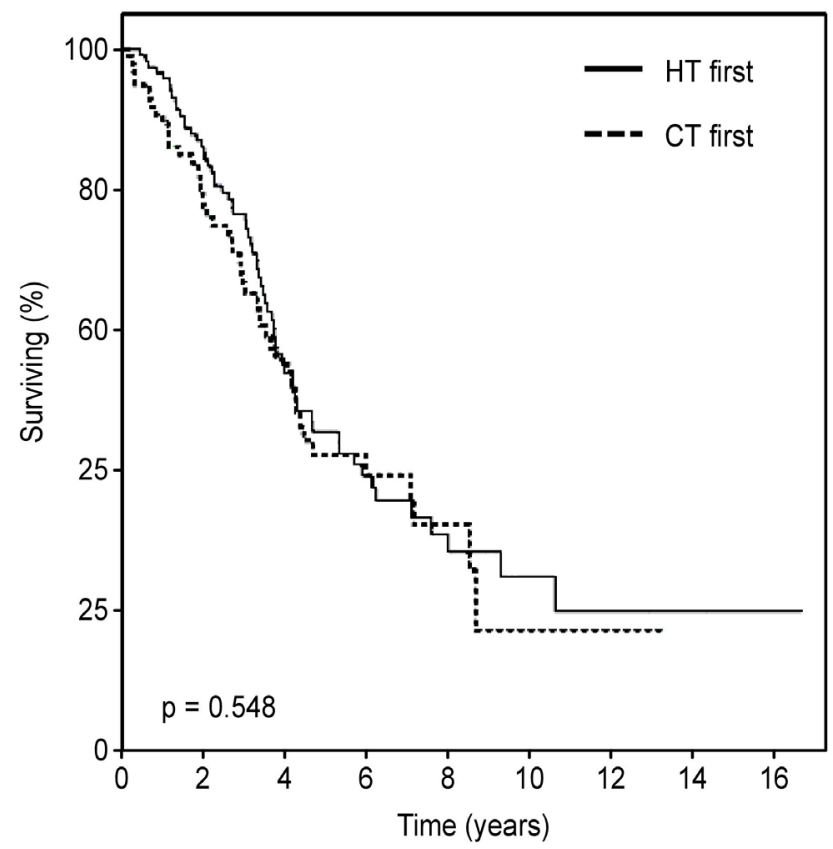

Number of patients at risk

$\begin{array}{llllllllll}\text { HT-first } & 119 & 95 & 42 & 24 & 11 & 5 & 4 & 2 & 1 \\ \text { CT-first } & 100 & 61 & 32 & 14 & 8 & 1 & 1 & & \end{array}$

Figure 2: Kaplan-Meier curves or overall survival according to treatment sequence. 


\section{Objective response and clinical benefit}

The ORR (CR or PR) observed after the firstline HT was not statistically different between the two sequence groups $(19.8 \%$ and $30.6 \%$ in the HT-first group and in the CT-first group, respectively, $p=0.094$ ). A similar result was observed when considering the first-line of CT $(27.5 \%$ and $38.9 \%$ in the HT-first and the CT-first groups, respectively, $p=0.134$ ).

No significant differences between the two treatment groups were observed in terms of CBR either after the first-line of HT $(75.9 \%$ versus $79.2 \%, p=0.6)$ nor the first-line of CT ( $73.9 \%$ versus $83.3 \%, p=0.147)$.

\section{PFS and overall survival}

Median follow-up was 3.14 years (range 0.12-16.70) and was similar for the two groups (3.31 years for the HT-first group and 2.89 years for the CT-first group, $p=$ 0.246).

PFS after the first-line treatment was comparable in the two groups, being 13.4 months (range 2.3-74.4) for the HT-first group and 13.9 months (range 1.6-114.0) for the CT-first group $(p=0.911)$.

Overall, 109 deaths were recorded: 62 in the HT-first group and 47 in the CT-first group. Median OS was 50.7 months $(95 \%$ CI 35.2-66.3) and 51.1 months $(95 \%$ CI 42.5 59.6) for the HT-first and the CT-first groups, respectively
( $p=0.548$, Figure 2). In the HT-first group, the percentage of surviving patients at $1,2,3,4$, and 5 years was $95.8 \%$, $86.1 \%, 76.5 \%, 53.9 \%$ and $45.5 \%$ respectively. The percentages observed in the CT-first group at the same time intervals were $89.5 \%, 77.4 \%, 66.7 \%, 55.7 \%$ and $42.1 \%$.

\section{Time spent in CT}

Figure 3 shows the estimates of the proportion of time/patients spent in CT during the follow-up. Data are truncated at the eighth year from starting therapy because beyond this time the small number of patients prevents to achieve reliable findings. At the beginning of therapy, the proportion of patients in $\mathrm{CT}$ in the CT-first group was much higher than in the HT-first group: indeed at the first year the estimates were 0.54 (95\% CI 0.46-0.60) and 0.11 (95\% CI 0.0-0.18), respectively. Over time, these proportions became closer: 0.34 (95\% CI $0.26-0.44)$ in CT-first group and 0.18 (95\% CI 0.11-0.27) in HT-first group within three years and $0.28(95 \% \mathrm{CI} 0.17-0.45)$ and $0.18(95 \%$ CI $0.09-0.31)$ respectively at the end of the investigated period.

\section{Univariate, multivariate and subgroup analyses}

In univariate analyses, the presence of visceral (liver, lung and/or brain) MTS and patients age were

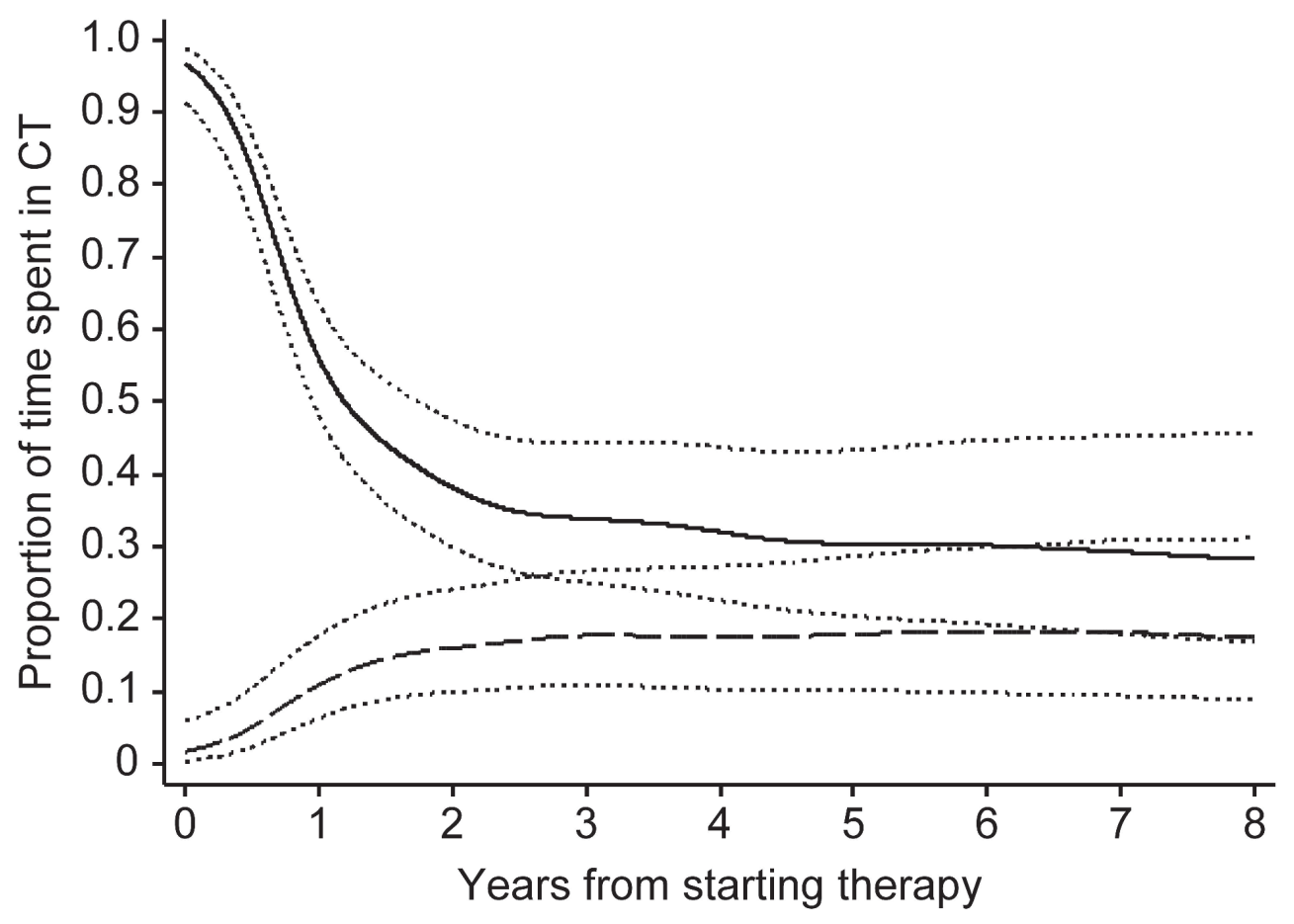

Figure 3: Time spent in CT (chemotherapy) related to OS (overall survival) in HT (hormonal-first group and in CTfirst group. CT-first group solid line; HT-first group dashed line; 95\%CI dot lines. 
significantly associated with OS ( $p=0.011$ and 0.047 , respectively). In multivariate analyses, only the presence of visceral MTS was a significant independent predictor of survival $(\mathrm{HR}=1.6,95 \% \mathrm{CI} 1.1-2.4, p=0.022)$.

Subgroup analyses of OS comparing the CT-first group versus the HT-first group within the strata of each prognostic factors indicated a possible interaction between treatment sequence and patient age; the significant higher HR of death in patients aged more than 65 years $(1.47$ versus $0.68, p=0.45)$ indicates that the HT-first sequence might be more effective in older patients in terms of OS (Figure 4). Conversely, no significant evidence of interaction was observed between the type of treatment sequence and menopausal status, presence of de novo metastatic disease, number of MTS sites, DDFS or presence of visceral or non-visceral MTS. Nevertheless, the HT-first sequence appeared favored in subgroups of patients at lower risk, that is in postmenopausal status, presenting a less aggressive disease (longer DDFS), with single non-visceral MTS.

\section{Prediction of the use of CT as first-line treatment of $\mathrm{MBC}$}

In univariate logistic regressions, the presence of de novo metastatic disease $(\mathrm{OR}=2.92, p<0.001)$, the presence of 2 or $\geq 3$ sites of MTS $(\mathrm{OR}=2.05$ and 2.91

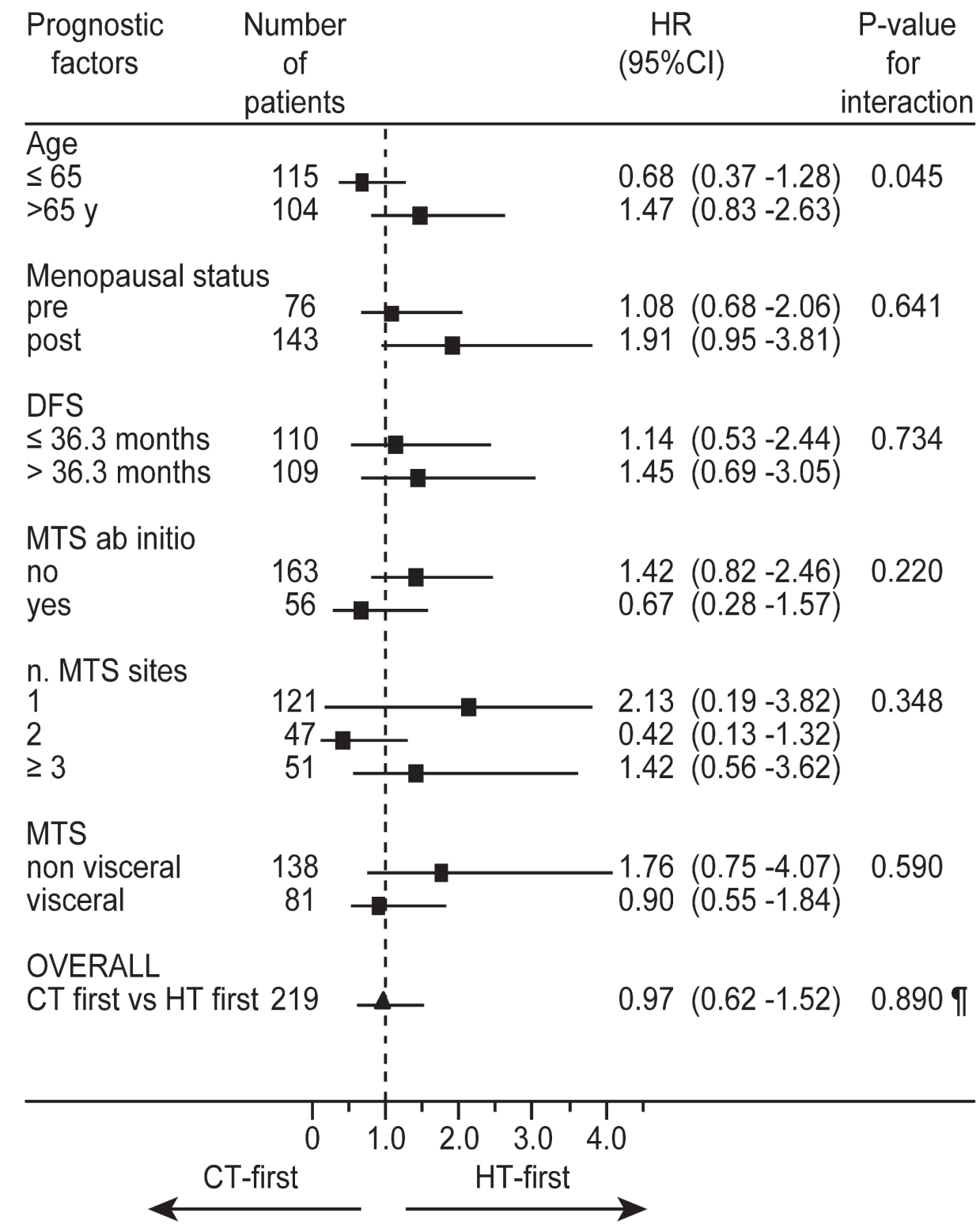

Figure 4: Forest plot of subgroup analyses of overall survival comparing the CT-first sequence versus the HT-first sequence within the strata of each prognostic factor. $\lceil$ overall comparison of CT-first sequence versus HT-first sequence adjusted for all prognostic factors. 
respectively, $p=0.001$ ) and the type of MTS (visceral versus non-visceral, $\mathrm{OR}=5.15, p<0.001$ ) were significant predictors of the use of CT as first-line treatment of MBC. On the contrary, older age $(>65$ years, $\mathrm{OR}=0.33, p<$ $0.001)$, postmenopausal status $(\mathrm{OR}=0.40, p=0.001)$ and long DDFS (OR $=0.48, p=0.0002)$ were significant predictors of the non-use of CT as first-line therapy (Table 3).

In multivariate regressions, de novo metastatic disease and MTS type were significant independent predictors of the preferential use of CT as first-line treatment ( $p=0.001$ and $p<0.001$, respectively) while patient age was significantly associated with the preferred non-use of CT $(p<0.001)$. By contrast menopausal status, a high number of MTS sites and a long DDFS were excluded from the final model $(p=0.102,0.400$ and 0.412 , respectively).

\section{DISCUSSION}

In our retrospective observational study, we observed that HR+/HER2- MBC patients treated with the sequence, first-line CT followed by HT, as compared with the reverse sequence, despite the poorer prognostic factors, showed a similar median OS of about 51 months. In the first three years, this result was obtained at the price of a longer of OS spent in CT for patients starting with CT as compared to patients treated with a first-line HT but this difference decreased after the third year and overall was $28 \%$ in CT-first group and $18 \%$ in HT-first group. Type of metastatic disease (visceral versus non-visceral) and younger age are strong predictors of the use of a first-line CT; the presence of visceral metastases is an independent adverse prognostic factor in $\mathrm{HR}+$ /HER2- MBC patients.

Our results are consistent with data of the literature showing that younger age and visceral metastases as adverse prognostic factors in HR+/HER2- MBC patients [17-19] and partially support current guidelines that indicate the presence of visceral metastases, although symptomatic, as the main criterion for choosing CT as first-line treatment of these patients [8-10].

Our study supports the results of older randomized trials [11] that showed no differences in terms of efficacy between HT and CT as first-line treatment of HR+ MBC patients. However, the absence of randomization allowed to treat patients at worse prognosis with CT obtaining the same results in terms of survival of the patients with a better prognosis treated with HT. Taking into account the median survival of about 4 years in patients with adverse prognostic factors, the beneficial effect of CT used as first-line treatment in this subgroup of patients cannot be excluded.

Our data are in line with those of a recent study showing that, in real life, a high percentage of patients with $\mathrm{HR}+$ disease receive initial $\mathrm{CT}$ in contrast with the recommendation of the current available guidelines [20].
Of note, the overall survival of patients treated with first-line CT in the study by Lobbezoo et al was worse (about 16 months) than the one of our patients ( about 51 months). This difference can be largely explained by the different patients' characteristics and pattern of cares in two studies (e.g. more bone disease and less multiple metastatic sites in our patients).

One recent observational study comparing CT versus HT as first-line treatment obtained our own results in terms of overall survival (37.5 months and 33.4 months respectively, log-rank test, $P=0.62$ ) and progression-free survival (13.3 months and 9.9 months respectively, logrank test, $P=0.92$ ) [21].

Another observational study showed that HR+ MBC patients receive a median of 3 lines of CT with approximately $40 \%$ of patients treated with fourth-line CT [22]. Our study confirmed that these patients received a median of 4 (HT-first group) or 3 (CT-first group) lines of treatment for their disease and median durations of HT and CT were the same in the two groups. However, to our knowledge, this is the first study showing that patients treated with $\mathrm{CT}$ as first-line treatment spend more time of their survival in CT as compared to patients starting with HT with a potential negative impact on their lives.

The main limitation of our study is its retrospective nature. This factor can lead to several bias including selection of patients and the choice of the treatment. On the other hand, no randomized trial of HT versus CT with treatments including currently used drugs, such as aromatase inhibitors, fulvestrant or taxanes, are available.

Patients included in this study were treated with modern HT and CT but they did not receive the most recently drugs everolimus (used only in two patients) or cyclin-dependent kinase 4/6 inhibitors (palbociclib or ribociclib). The improvements in efficacy obtained in randomized trials from the combination of everolimus and exemestane [23] or palbociclib with letrozole [24] or with fulvestrant [25], or ribociclib plus letrozole [26] could lead in the future to better outcomes with HT and with less use of $\mathrm{CT}$ in $\mathrm{HR}+/ \mathrm{HER} 2-\mathrm{MBC}$ patients.

Moreover, another important limitation is that our study does not answer the question whether HT in maintenance should be given.

In conclusion, our study suggests that HR+/HER2MBC patients treated with first-line CT followed by HT, despite the poor prognostic factors, had clinical outcomes similar to those of patients treated with the reverse sequence. However, these results are obtained at the price of a longer time of OS spent in CT.

\section{CONFLICTS OF INTEREST}

All authors declare that they do not have any conflicts of interest relevant to the subject of this manuscript. 
FUNDING

We have not any founding source to declare.

\section{ETHICAL APPROVAL}

The study was approved by the Institutional Ethic Committee of IRCCS-AOU San Martino National Cancer Institute of Genoa (Italy). All alive patients gave their written informed consent to personal data management for scientific purposes. For death patients all information were anonymized and de-identified prior to analysis.

\section{REFERENCES}

1. Perou CM, Sørlie T, Eisen MB, van de Rijn M, Jeffrey SS, Rees CA, Pollack JR, Ross DT, Johnsen H, Akslen LA, Fluge O, Pergamenschikov A, Williams C, et al. Molecular portraits of human breast tumours. Nature. 2000;406:747752.

2. Sørlie T, Perou CM, Tibshirani R, Aas T, Geisler S, Johnsen H, Hastie T, Eisen MB, van de Rijn M, Jeffrey SS, Thorsen $\mathrm{T}$, Quist H, Matese JC, et al. Gene expression patterns of breast carcinomas distinguish tumor subclasses with clinical implications. Proc Natl Acad Sci USA. 2001;98:1086910874.

3. Sotiriou C, Neo SY, McShane LM, Korn EL, Long PM, Jazaeri A, Martiat P, Fox SB, Harris AL, Liu ET. Breast cancer classification and prognosis based on gene expression profiles from a population-based study. Proc Natl Acad Sci USA. 2003;100:10393-10398.

4. Senkus E, Cardoso F, Pagani O. Time for more optimism in metastatic breast cancer?. Cancer Treatment Reviews. 2014;40:220-228.

5. Tan SH, Wolff AC. Diseases of the Breast 4th edn. Cedar Knolls, New Jersey: Lippincott Williams \& Wilkins, 2009; Chapters: 73-74.

6. Martín M, Loibl S, von Minckwitz G, Morales S, Martinez N, Guerrero A, Anton A, Aktas B, Schoenegg W, Muñoz M, Garcia-Saenz JÁ, Gil M, Ramos M, et al. Phase III trial evaluating the addition of bevacizumab to endocrine therapy as first-line treatment for advanced breast cancer: the letrozole/fulvestrant and avastin (LEA) study. J Clin Oncol. 2015;33:1045-1052.

7. Cardoso F, Harbeck N, Fallowfield L, Kyriakides S, Senkus E. ESMO Guidelines Working Group. Locally recurrent or metastatic breast cancer: ESMO Clinical Practice Guidelines for diagnosis, treatment and follow-up. Ann Oncol. 2012;23:vii11-vii19.

8. Cardoso F, Costa A, Senkus E, Aapro M, André F, Barrios $\mathrm{CH}$, Bergh J, Bhattacharyya G, Biganzoli L, Cardoso MJ, Carey L, Corneliussen-James D, Curigliano G, et al. 3rd ESO-ESMO international consensus guidelines for Advanced Breast Cancer (ABC 3). Breast. 2017;31:244-
259.

9. NCCN Guidelines, Breast Cancer version 2.2016, Available at www.nccn.org/professional/physician_gls/pdf/breast.pdf. Accessed November 24, 2016.

10. Partridge AH, Rumble RB, Carey LA, Come SE, Davidson NE, Di Leo A, Gralow J, Hortobagyi GN, Moy B, Yee D, Brundage SB, Danso MA, Wilcox M, et al. Chemotherapy and Targeted Therapy for Women With Human Epidermal Growth Factor Receptor 2-Negative (or unknown) Advanced Breast Cancer: American Society of Clinical Oncology Clinical Practice Guideline. J Clin Oncol. 2014;32:3307-3331.

11. Wilcken N, Hornbuckle J, Ghersi D. Chemotherapy alone versus endocrine therapy alone for metastatic breast cancer. Cochrane Database Syst Rev. 2003; CD002747.

12. Dufresne A, Pivot X, Tournigand C, Facchini T, Alweeg T, Chaigneau L, De Gramont A. Maintenance hormonal treatment improves progression free survival after a first line chemotherapy in patients with metastatic breast cancer. Int J Med Sci. 2008;5:100-105.

13. Coates AS, Winer EP, Goldhirsch A, Gelber RD, Gnant M, Piccart-Gebhart M, Thürlimann B, Senn HJ; Panel Members. Tailoring therapies - improving the management of early breast cancer: St Gallen International Expert Consensus on the Primary Therapy of Early Breast Cancer 2015. Ann Oncol. 2015;26:1533-1546.

14. Therasse P, Arbuck SG, Eisenhauer EA, Wanders J, Kaplan RS, Rubinstein L, Verweij J, Van Glabbeke M, van Oosterom AT, Christian MC, Gwyther SG. New guidelines to evaluate the response to treatment in solid tumors. European Organization for Research and Treatment of Cancer, National Cancer Institute of the United States, National Cancer Institute of Canada. J Natl Cancer Inst. 2000;92:205-216.

15. Kaplan EL, Meier P. Nonparametric estimation from incomplete observations. JASA. 1958; 53: 457-481.

16. Cleveland WS, Devlin S. Locally-Weighted Regression: An Approach to Regression Analysis by Local Fitting. Journal of the American Statistical Association. 1988;83:596-610.

17. Clark GM, Sledge GW Jr, Osborne CK, McGuire WL. Survival from first recurrence: relative importance of prognostic factors in 1,015 breast cancer patients. J Clin Oncol. 1987;5:55-61.

18. Solomayer EF, Diel IJ, Meyberg GC, Gollan C, Bastert G. Metastatic breast cancer: clinical course, prognosis and therapy related to the first site of metastasis. Breast Cancer Res Treat. 2000;59:271-278.

19. Largillier R1, Ferrero JM, Doyen J, Barriere J, Namer M, Mari V, Courdi A, Hannoun-Levi JM, Ettore F, BirtwislePeyrottes I, Balu-Maestro C, Marcy PY, Raoust I, et al. Prognostic factors in 1,038 women with metastatic breast cancer. Ann Oncol. 2008;19:2012-2019.

20. Lobbezoo DJ, van Kampen RJ, Voogd AC, Dercksen MW, van den Berkmortel F, Smilde TJ, van de Wouw AJ, 
Peters FP, van Riel JM, Peters NA, de Boer M, Peer PG, Tjan-Heijnen VC. In real life, one-quarter of patients with hormone receptor-positive metastatic breast cancer receive chemotherapy as initial palliative therapy: a study of the Southeast Netherlands Breast Cancer Consortium. Ann Oncol. 2016; 27:256-262.

21. Bonotto M, Gerratana L, Di Maio M, De Angelis C, Cinausero M, Moroso S, Milano M, Stanzione B, Gargiulo P, Iacono D, Minisini AM, Mansutti M, Fasola G, et al. Chemotherapy versus endocrine therapy as first-line treatment in patients with luminal-like HER2-negative metastatic breast cancer: A propensity score analysis. Breast. 2017;31:114-120.

22. Seah DS, Luis IV, Macrae E, Sohl J, Litsas G, Winer EP, Lin NU, Burstein HJ. Use and duration of chemotherapy in patients with metastatic breast cancer according to tumor subtype and line of therapy. J Natl Compr Canc Netw. 2014;12:71-80.

23. Baselga J, Campone M, Piccart M, Burris HA 3rd, Rugo HS, Sahmoud T, Noguchi S, Gnant M, Pritchard KI, Lebrun F, Beck JT, Ito Y, Yardley D, et al. Everolimus in postmenopausal hormone-receptor-positive advanced breast cancer. N Engl J Med. 2012;366:520-9.
24. Finn RS, Crown JP, Lang I, Boer K, Bondarenko IM, Kulyk SO, Ettl J, Patel R, Pinter T, Schmidt M, Shparyk Y, Thummala AR, Voytko NL, et al. The cyclin-dependent kinase 4/6 inhibitor palbociclib in combination with letrozole versus letrozole alone as first-line treatment of oestrogen receptor-positive, HER2-negative, advanced breast cancer (PALOMA-1/TRIO-18): a randomised phase 2 study. Lancet Oncol. 2015;16:25-35.

25. Turner NC, Ro J, André F, Loi S, Verma S, Iwata H, Harbeck N, Loibl S, Huang Bartlett C, Zhang K, Giorgetti C, Randolph S, Koehler M, et al. Palbociclib in HormoneReceptor-Positive Advanced Breast Cancer. N Engl J Med. 2015;373:209-19.

26. Hortobagyi GN, Stemmer SM, Burris HA, Yap YS, Sonke GS, Paluch-Shimon S, Campone M, Blackwell KL, André F, Winer EP, Janni W, Verma S, Conte P, et al. Ribociclib as First-Line Therapy for HR-Positive, Advanced Breast Cancer. N Engl J Med. 2016;375:1738-1748. 